\title{
В.Ю. МИНЕРАЛОВ
}

\section{ПЕРСПЕКТИВЫ АКТИВИЗАЦИИ И РАСПРОСТРАНЕНИЯ СОЗИДАТЕЛЬНОГО ТВОРЧЕСТВА КАК УСЛОВИЕ ОБЩЕСТВЕННОГО ПРОГРЕССА}

Представлен многоаспектный анализ эволюции понятия «креативность». Особый акцент сделан на рассмотрении взаимосвязанных общественных процессов, как способствующих изменению значения креативности, так и являющихся следствием роста творческого потенциала личности. Раскрыты позитивные и негативные перспективы развития массовой креативности и обусловливающие их конкретные социальные, культурные и экономические явления.

Ключевые слова: креативность, креативный класс, рациональное действие, креативное действие, новаторство, культура, социальные связи, социальная ответственность.

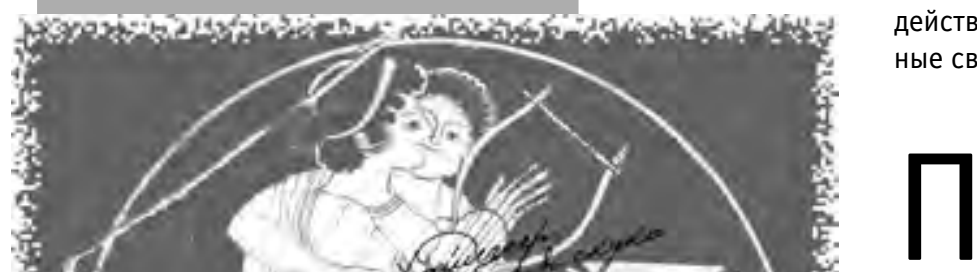

рогресс человеческой цивилизации, отдельных государств и организаций в современном мире многими исследователями (Д. Белл, П. Друкер, Э. Тоффлер, Р. Флорида и др.) связывается с ростом новаторства, творческого потенциала, предприимчивостью и креативностью. На подобных идеях основаны теории общества знаний, постиндустриального общества и др. Несмотря на то, что проблемы творчества, креативности, таланта и одаренности исследуются уже давно, по-прежнему остаются и появляются новые вопросы, требующие прояснения. Пробелы в научных знаниях касаются не столько природы творчества, сколько эволюции представлений о творчестве (сегодня зачастую как синоним используют понятие «креативность»), о его месте в развитии общества, практических проявлениях. Общая тенденция такой эволюции заключается, прежде

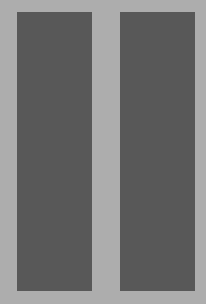

\section{КУЛЬТУРНАЯ РЕАЛЬНОСТЬ}


всего, в переходе от идеи избранности (творчества как некоего божественного или природного дара), элитарности к массовости, креативным способностям каждого человека, возможности выявления и развития неочевидных талантов, устранения социальных и природных препятствий на пути творческого раскрытия и самореализации личности.

На практике, говорят сторонники «замены термина», происходит общественное рассеивание, более равномерное распределение творческих способностей, формирование условий, в которых крупные общественные фигуры, гении уходят на второй план. При этом всякого рода новаторство в значительной мере связывается не с мистическим озарением, а с ежедневными усилиями простых людей, скрупулезно выявляющих неочевидные связи известных явлений и возможности решения проблем. При подобной интерпретации творчества и креативности усиливается риск снижения качества продуктов творчества, искажения представлений о природе творчества, ценных и приемлемых его проявлениях.

Ставшее своего рода диагнозом времени стремление к рационализации и строгой целевой ориентации творческого процесса, к оценке результатов творчества с позиции целесообразности и попытки механизировать творческую активность, превратить в набор операций, алгоритмов, с одной стороны, и настойчивые либеральные призывы к ничем не сдерживаемому самовыражению с другой, требуют внимательного исследования.

Прежде чем перейти к анализу современных социологических интерпретаций феномена творчества и лежащей в его основе креативности, рассмотрим, как понимаются данные человеческие способности на индивидуально-психологическом уровне.

Креативность (от лат. creatio - созидание) - общая способность к творчеству, характеризует личность в целом, проявляется в различных сферах активности, рассматривается как относительно независимый фактор одаренности [1, с. 353]. Суть креативности («творческости») как психологического свойства сводится, по Я.А. Пономареву, к интеллектуальной активности и чувствительности (сензитивности), к побочным продуктам своей деятельности. Для творческого человека наибольшую ценность представляют побочные результаты деятельности, нечто новое и необычное [2, с. 21-25].

Существует точка зрения на творчество и деятельность как принципиально противоположные формы человеческой активности. Творчество, являясь особой формой активности, бескорыстно, непланируемо, амотивно, нецелесообразно, непроизвольно, иррационально и не поддается (в момент творческого акта) регуляции со стороны сознания - это спонтанное проявление человеческой сущности. Для творческого акта характерно рассогласование цели (замысла, программы и т. д.) и результата. В отличие от творческой активности деятельность (как форма человеческой активности) целесообразна, произвольна, рациональна и сознательно регулируема, ориентирована на результаты по достижению цели, а не новизну. Основ- ным признаком деятельности является потенциальное соответствие цели деятельности ее результату.

Творческая активность может возникать в процессе осуществления деятельности и связана с порождением «побочного продукта», который и является в итоге творческим результатом [1, с. 159-168].

Иными словами, творчество и деятельность с точки зрения психологии рассматриваются как противоположности. Однако они не существуют изолированно и в процессе осознанной, целенаправленной и запланированной деятельности нередко рождаются неожиданные «открытия», которые могут при определенных условиях оказаться более ценными, чем изначально прогнозируемые результаты деятельности, быть признанными в качестве новых достижений в той или иной области жизни, воплотиться в полезных инновациях.

Приведенные психологические характеристики творчества и деятельности соответствуют, прежде всего, идеальным условиям, в реальности не выделяются столь явно и зачастую оказываются взаимообусловленными.

Проявления творчества различаются интенсивностью выраженности, которая не обязательно коррелирует с общественной ценностью. Л.А. Китаев-Смык выделяет три уровня творчества:

- компилятивный уровень связан с собиранием, классификацией, рубрикацией, ранжированием уже известных разрозненных знаний и фактов;

- проективный уровень имеет место, когда создаются обобщенные новые суждения на основании собранных знаний;

- инсайтно-креативный уровень связан с озарением, когда творец неожиданно постигает что-то новое, неожиданное для него [3, с. 72].

Наиболее часто третий уровень творчества проявляется в области экспрессивно-выразительного художественного творчества и искусства, реже в науке; первый и второй уровни более характерны также для науки и особенно производственной деятельности, предпринимательства и управления.

Некоторые ученые рассматривают творчество в качестве наивысшей формы самореализации личности. Интересную точку зрения, характеризующую первостепенное значение творчества, высказывает В.М. Вильчек. По его мнению, творчество представляется особым видом труда, осуществляемого за определенную сумму благ, необходимую автору для того, чтобы удовлетворить свои базовые потребности (в еде, отдыхе, безопасности и т. п.). Труд является лишь способом удовлетворения потребности, никакой потребности в труде как таковом (его обобщении - целесообразной деятельности) не существует. «Но в критических ситуациях всегда будут выявляться различия между творчеством и трудом, выявляться грубо и зримо. Человек никогда не борется за право трудиться - даже если и выступает под лозунгом за право на труд. На самом деле он борется за право иметь средства к существованию и за свой социальный статус. Но за право на творчество, за созданные идеи, образы люди шли на 
костер. Любые подделки и суррогаты создаются за деньги, и лишь шедевры - даром. Если автору за них что-либо и платят, то и вовсе по глупости, ибо не понимают, что великие творения духа - научные, художественные, любые - создаются и тогда, когда за них расплачиваются не с автором, а сами авторы: порой бедностью и лишениями, порой свободой, порой жизнью» [4, с. 20].

Такое суждение соответствует действительности с той оговоркой, что нередко понимаемое окружающими как «труд» для конкретного человека является формой самореализации, самовыражения, в том числе реализации креативных способностей. В силу привычки, воспитания, убеждений, интересов определенный труд становится добровольным, он выполняется не по принуждению, не ради обретения средств к существованию или социального статуса, а является одним из главных смыслов жизни человека, за который он готов бороться.

Упомянутые точки зрения на природу креативности и творчества полезны в качестве научной основы для дальнейшего анализа данных явлений в социологическом измерении ${ }^{1}$.

Переходя к социологической интерпретации креативности необходимо отметить, что нельзя непосредственно экстраполировать данные психологии личности на социальные явления. Важно помнить, что общественные условия, оценки накладывают отпечаток не только на процесс, но и продукт творчества. Общественно разделяемые нормы, правила, ценности и цели стимулируют или ограничивают креативность, ведут к поддержке и признанию одних проявлений и обесцениванию с общественной, коллективной точки зрения других. Выявленные психологическими методами высокие творческие способности далеко не всегда могут проявиться в социально одобряемом результате, быть по достоинству оцененными обществом.

Одна из наиболее значительных работ, в которой креативность изучается с социологических позиций, теория креативности человеческого действия X. Йоаса. Здесь креативность предстает не просто как способность каждого человека, но как важнейшая основа развития общества, его творческого самоконструирования.

Согласно Х. Йоасу, модель креативного действия охватывает господствующие ныне модели рационального и нормативно-ориентированного действия [5, с. 13]. В соответствии с таким представлением человек действует не только исходя из рационального расчета выдвигая цели, оценивая и изыскивая средства для их достижения и планируя получение определенного результата. Так же как не всегда действия человека ориентированы на следование установленным обществом, государством, коллективом нормам, подкрепленным санкциями.

\footnotetext{
${ }^{1}$ Далее, в связи с распространенностью во многих социологических работах термина «креативность», будет использоваться преимущественно этот термин, подразумевая под креативностью общую способность к творчеству.
}

На практике рационально действующий субъект в большинстве случаев вынужден изыскивать и даже создавать средства, творчески генерировать планы и стратегии и т. д. Следование нормам не предполагает только конформизм, но «требует рискованных разработок, абсолютно новых алгоритмов действия» [5, с. 260], конкретизации норм и ценностей в определенных условиях или даже их изменения в соответствии с изменениями ситуации. Это вынуждает субъекта мыслить и действовать креативно.

Содержащаяся в рациональном и нормативно ориентированном типах действия креативность позволяет их интегрировать в модель креативного действия.

Рассматривая метафоры креативности, Х. Йоас справедливо критикует попытки свести понимание человеческого действия к выразительному (экспрессивному), производственному (утилитарному) или революционному, рассматривать человеческое действие приоритетно через призму одной из названных теорий. В широком понимании нельзя свести человеческую креативность, ее проявления только к художественному выражению, к искусству, как бы ни были сильны в нем экспрессивные начала и проявления креативности, миру материальных объектов, производственных отношений (науке, экономике, технике) или к революционным преобразованиям социальной среды, общественных институтов. Продуктом творчества могут быть не только произведения искусства, но и результаты науки, производства, управления, предпринимательства. Достижение консенсуса в политической ситуации также требует креативных усилий. Соответственно может существовать и политическая креативность [5, с. 130-131]. Частное разделение на виды творчества и сферы проявления необходимо, но не должно подменять многогранности феномена креативности (творчества) как безусловный приоритет.

В современных условиях, в контексте моды на креативность попытки выставить какую-то сторону этого явления безусловно доминирующей, нуждающейся во всевозможном поощрении и поддержке (в частности, экспрессивная креативность) неоправданно оставляют без внимания другие общественно ценные формы ее реализации.

Креативность может культивироваться не только в искусстве, производственном труде, профессиональной деятельности, но и в сфере досуга, где человек способен быть не просто потребителем продуктов, услуг, произведенных «профессионалами», но и сам организовывать свой досуг, заниматься сотворчеством и творчеством, управляя этими процессами. Поэтому конец общества труда вовсе не означает упадок креативности, скорее наоборот.

Ошибочным является лишение каких-либо конкретных типов действия любых творческих характеристик и понимание их в качестве противоположности креативности. Например, экспрессивное художественное самовыражение наиболее заметно окружающим, и человек, оце- 
нивая себя по своим высказываниям, действиям и отклику окружающих на свои действия, скорее осознает свою креативность, выражаясь экспрессивно. Остальные же возможности, заложенные в человеке, иные проявления креативности реже оказываются понятыми, замеченными, оцененными даже самим их носителем - действующим субъектом.

При таком подходе тот, кто не может выразить себя, к примеру в поэзии, предстает ограниченным и скучным обывателем, чьи формы выражения не заслуживают внимания. Таким образом, отождествление одного конкретного типа действия с определением «креативности» приводит к обесцениванию других типов действия. Альтернатива этой неудачной формы образования понятий заключается в трактовке креативности как измерения потенциально любого человеческого действия [5, с. 131].

Рассуждая о креативности человеческого действия, важно помнить, что действия отличаются разной мерой креативности. Креативные действия и найденные на их основе новые решения проблемы постепенно преобразуются в рутинные действия, новую норму, привычку. В процессе этого перехода действия все более теряют свой креативный потенциал. Движение от креативного к рутинному отследить непросто, поскольку оно происходит с разной скоростью в зависимости от личности, условий, вида деятельности и т. д.

Зачастую креативность и рутина тесно переплетены, и действия постоянно переходят от одного полюса к другому. Креативность, возникает на основе рутины, привычки, опыта, знаний, и новое решение, знание, действие вновь становится привычным опытом, традицией, признанным знанием. Рутина - это результат креативности и среда, ресурс для следующих креативных действий.

Взяв за основу идеи, заложенные в «гуманистической психологии» А. Маслоу, Х. Йоас выделяет понятие «всеобъемлющей креативности».

Согласно А. Маслоу, существует первичная, вторичная и интегрированная креативность. Первичная креативность основывается на высвобождении «первичных процессов» фантазии и воображения, игрового и энтузиастического начал, не обремененных какими-то определенными целями и ценностями. Вторичная креативность требует значительного самоконтроля, целенаправленности и ориентирована на рациональное производство нового в мире, будь то решения технических или научных, а также различных художественных и повседневно-практических проблем - то, что обобщенно можно назвать «прогрессом общества».

Однако возможна интеграция первичной и вторичной креативности, приводящая к высшей креативности, сохраняеющей некоторую дистанцию по отношению ко всему рациональному и нормативному, сковывающему «цепями» правил, норм, обязательных ценностей, целей, но не отвергающему полностью контроль со стороны рациональности и критики. В этом понятии «интегрированной креативности» открытость самовыражения объединяется с ответственностью самоконтроля, что требует наличия условий для автономии личности, которая бы не приобреталась за счет моральной деградации [6, с. $180-185]$.

Сам А. Маслоу так разъясняет понятие высшей креативности: «для создания великого произведения требуется не только просветление, вдохновение, пиковое переживание, оно также требует тяжкого труда, большого опыта, беспощадно-критического отношения к самому себе, стремления к совершенству. Иными словами, замысел доминирует над спонтанностью, критическое отношение доминирует над абсолютной терпимостью, строгая мысль доминирует над интуицией, осторожность доминирует над дерзанием, критерий реальности доминирует над фантазией и воображением» [6, с. 183].

Современным тенденциям высвобождения, развития и реализации креативности сопутствует высокая динамика трансформации индивидуальных и общественных ценностей. Формирующееся в развитых странах поколение креативных людей обладает особыми ценностными ориентациями, характеризующимися такими понятиями, как экспрессивность, креативность и аутентичность. Представители этого поколения желают освоить профессии, которые, как им кажется, примиряют профессиональную и частную жизнь - утилитарную и экспрессивную креативность [5, с. 281]. На личностном уровне развитие креативности нередко сопровождается нежеланием подчиняться инструкциям организаций и институтов и сопротивлением традиционным групповым нормам, стойкой приверженностью индивидуальному своеобразию.

Все больше людей осознают свою творческую индивидуальность, у них усиливается стремление к самовыражению, самореализации, и это имеет как позитивные, так и негативные следствия. Индивидуализм и безответственный «творческий» эгоизм могут усугублять конфликт интересов, вести к общественным катаклизмам, разрыву солидарных связей, снижению доверия и слаженности общественной системы в целом. Позитивная сторона вопроса проявляется в том, что осознание собственной творческой индивидуальности, творческих способностей (креативности) благоприятствует формированию более активной и ответственной общественной позиции (предприимчивости), участию в общественной жизни, управлении. Это потенциально минимизирует общественные риски, позволяет избежать кризиса управления, зависимости лишь от группы людей, непосредственно находящихся у власти, обеспечивая возможность в случае кризиса централизованной власти за счет общественной самоорганизации, самоуправления удержать общество, государство от распада.

Другая положительная тенденция - активизация разных форм и видов новаторства и рационализаторства, а также, что чрезвычайно важно, стремление к гармонизации общественной жизни через самореализацию в творчестве.

Характерной чертой эволюции проявлений индивидуальной креативности выступают коммерциализация и борьба за статус. Особо можно выделить проблему по- 
давленной креативности. Х. Йоас связывает эти явления с понятиями «яппизации»².

Рассмотрим проблему «яппизации», которая, согласно Х. Йоасу, обозначает сглаживание отношений напряженности между нормативностью и креативностью, происходящее в результате радикального устранения морали как в утилитаристском, так и в экспрессивном индивидуализме. С понятием «яппи» Х. Йоас связывает «представление о таком типе людей, которые не испытывают угрызений совести, используя любые средства для достижения экономического и профессионального успеха или наслаждаясь роскошью и удовольствиями, которые им дает их стиль жизни и досуга. Алчность и карьерная похоть так же лишены морального содержания, как и расточительство, и демонстративное потребление в условиях социального неравенства. Признаки явления «яппи» он видит «в любой неспецифической жадности до новых впечатлений ради самой новизны и во всех стилях жизни, которые появляются без всякой претензии на универсальную значимость» [5, с. 285].

Как бы продолжая рассуждения Х. Йоаса о возможной моральной деградации, сопровождающей высвобождение креативности, американский исследователь социально-экономических проблем креативности Р. Флорида, развивая понятие «креативный класс» ${ }^{3}$ [7, с. 85], подчеркивает: «...представители креативного класса слишком склонны были жить в мире личных интересов, эгоистически преследуя частные цели и не задумываясь о других людях и социальных проблемах. Они погрязли в самодовольстве и зачастую бессмысленном существовании, испытывая при этом все большую неудовлетворенность таким положением вещей» [7, с. 14].

Участившиеся попытки возведения креативности в разряд преимущественно экономических ресурсов девальвируют ее ценность, давая ей оценку лишь в экономическом измерении, подчиняя творчество исключительно утилитарным целям. Негативные стороны так называемой креативной экономики проявляются в коммерциализации многих форм культуры, снижении эстетического качества, художественного мастерства нравственно-воспитательной ценности.

Отождествление креативности, творческих способностей с экономическими достижениями, материальным успехом, карьерой, деньгами порождает множество псевдокреативных спекулянтов - людей, которые на волне моды на креативность и ее материального поощрения, ловко имитируя творчество, создают креативную экономику как систему спекуляции низкокачественным подобием творческих продуктов. Их инструмент - красивые фразы и громкие лозунги, коммерческая нахрапистость и беспринципная ложь. Несомненно, что коммерческий

\footnotetext{
${ }^{2}$ Яппи - молодые состоятельные люди, ведущие активный светский образ жизни, построенный на увлечении профессиональной карьерой и материальном успехе [5].

3 Упрощенно под креативным классом можно понимать сообщество представителей профессий и видов деятельности, в которых требуется значительная доля креативности.
}

успех никогда не был и не может быть главным показателем качества и пользы результатов творчества.

Многие факты указывают на то, что попытки культивировать экономическую рациональность поведения как неоспоримую ценность и самоцель способствуют развитию гипертрофированного индивидуализма и эгоиза, разрушающих всякую искреннюю солидарность, социальность под натиском собственничества и нарциссического самовыражения.

Нередко в повседневном сознании встречается искаженное понимание рациональности как потакание всем своим потребностям, стремлениям и капризам без учета интересов окружающих или в ущерб им. Такая точка зрения иррациональна в своей основе, так как подразумевает разрушительную «войну всех против всех».

Ранее упоминалось, что проявления креативности не противоречат рациональности. Полет фантазии, озарение и вдохновение во многих сферах и конкретных случаях требуют также логически взвешенного рационального решения с учетом существующих норм и правил, знаний, условий среды. Только в этом случае хорошая идея, разработка - любое креативное действие - могут воплотиться в полезном новшестве, продукте творчества. При этом рациональный расчет, нормы, цели и правила не должны быть незыблемыми, а, напротив, при необходимости должны подвергаться пересмотру и изменению, креативной переработке.

Общественно полезное творчество - это всегда поиск баланса между свободой индивидуального экспрессивного или утилитарного самовыражения и рациональностью и нормативностью.

Критика чрезмерного включения рациональности в творческий процесс, прежде всего, направлена на преследование экономических интересов. Симптомами социальной болезни, ведущей к прогрессирующему распаду общественных связей, устранению обязательных ценностных ориентиров, к аномии, представляются многим исследователям попытки необдуманного переноса экономических принципов в сферу творчества, особенно связанного с культурой, воспитанием и образованием, а во многих случаях и наукой. Опасения связаны с возвышением всего вульгарного и низкокачественного, но коммерчески выгодного в культуре (на фоне высмеивания и принижения любого бескорыстного, коммерчески неуспешного творчества); с тотальной подменой фундаментальных знаний исключительно утилитарными знаниями и индивидуализированными ценностями в образовании; с постепенным вытеснением обязательной установки на семейные и коллективные ценности из процесса воспитания; с ориентацией науки на решение экономически прибыльных краткосрочных и среднесрочных задач в ущерб долгосрочным, перспективным, а также снижением поддержки научно-теоретической деятельности, предполагающей выявление и анализ тех или иных феноменов и процессов, а не поиск готовых рецептов решения проблем.

Отдельно можно выделить небезосновательные опасения снижения, в угоду экономической рациональности, 
значения самоценности творчества, понимания творчества как высшей формы самореализации личности, ведущей к гармоничному развитию индивидов. Именно развитие общественной креативности в долгосрочной перспективе создает возможность перехода от общества «вынужденного труда» к креативному обществу гармоничного созидания.

Важно сохранять взвешенное критическое отношение к попыткам коммерциализации творчества, искореняющей всякий альтруизм, общественное служение, бездумно насаждающей коммерческие, рыночные, деловые отношения. Так называемые творческие, или креативные, индустрии (creative industries) ${ }^{4}$, соединяющие бизнес-навыки и культурные практики, создающие за счет индивидуального творчества добавочную стоимость, ориентированные на производство и эксплуатацию интеллектуальной собственности [8], в стратегической перспективе не могут быть главной целью развития креативности и не должны в погоне за прибылью принижать ценность бескорыстного, самодостаточного творчества.

Р. Флорида призывает творчески реализовавшихся, добившихся определенного социального и материального успеха и статуса людей превратиться из аморфного сборища самонадеянных, пусть и преуспевающих, индивидов в более сплоченную, более ответственную группу, гарантирующую возможности социальной мобильности, открытости как физических, так и культурных границ для каждого человека, стремящегося к развитию и реализации своих творческих способностей [7, с. 343]. Автор подчеркивает: «элитарность, неравенство, неэффективность и даже опасность содержатся в сохранении общественного порядка, при котором некоторые люди воспринимаются как прирожденные творцы, а остальные существуют, чтобы их обслуживать, воплощать их идеи и удовлетворять их потребности. Ограничение креативности кругом избранных - настоящий рецепт всякого рода проблем, от социальной несправедливости до неэффективности» [7, с. 350].

Рассмотренные негативные тенденции развития индивидуальной и общественной креативности актуализируют необходимость выработки новых форм гражданской активности, социальных связей, компенсирующих ослабление традиционных социальных взаимодействий в результате индивидуализации, возрастающей пространственной мобильности и разнообразия жизненных планов, ценностей, целей и форм самовыражения.

Желание принимать творческое участие в общем деле, которое бы имело значимые последствия, поддерживать связь с социальной общностью, противостоящее тенденциям ухода в частную жизнь, содержится в предлагаемом Х. Йоасом понятии «партиципация». Рациональное преследование интересов, моральное обязательство

\footnotetext{
${ }^{4} \mathrm{~K}$ креативным индустриям некоторые авторы относят музыку, изобразительные искусства, кино, исполнительские искусства, галерейный бизнес, моду, ремесла, издательское дело, рекламу, дизайн, архитектуру, Интернет и компьютерные технологии, культурный туризм.
}

и креативное самораскрытие могут переживаться как одно целое в организациях и институтах демократической политики и культуры, а также в социальных движениях, которые представляют собой подвижную основу демократии. «Партиципация только тогда является практической формой интегрированной креативности, когда она представляет собой не только преследование корыстных интересов или чисто нормативное обязательство, оторванное от разворачивающегося в частной сфере самораскрытия. <...> Партиципация заключается в том или ином индивидуальном балансе различных образов действия» [5, c. 284-285].

Перспективным представляется дальнейший поиск и налаживание социальных связей, способствующие аккумулированию творческого потенциала общества путем включения креативной активности многих индивидов в ответственную и созидательную деятельность.

В этих целях, например, может быть использована модель конструктивного социального взаимодействия, согласно которой инноватор отклоняется от традиционных самоочевидностей коллектива в когнитивном или нормативном отношении, но при этом отстаивает свое новое видение мира с помощью аргументов. Коллектив может или отказаться от этих аргументов, или прислушаться к ним. Существует дискурсивное отношение между инноватором и коллективом. Не только инноватор возвышается над старыми нормами, но и «коллектив способен к некого рода гипотетическому дистанцированию по отношению к собственным нормам» [5, с. 58].

Важная задача стоит, прежде всего, перед наиболее способными и творчески реализовавшимися членами общества, которым следует не только осознать необходимость массовой активизации креативности, но и суметь предложить реалистические пути повышения уровня жизни через реализацию креативности граждан в экономической и социально-культурной деятельности.

Возможная форма практического баланса рациональности и креативности представлена в инвестиционной теории креативности Р. Стернберга и Т. Любарта, в соответствии с которой проявление, развитие и реализация креативности зависит от когнитивных, личностных и мотивационных ресурсов человека, а также от условий среды. В ходе мыслительной деятельности, согласно этой теории, необходимо отбросить бесперспективные варианты и выбрать оптимальные. Поэтому креативность подразумевает чередование дивергентного и конвергентного мышления [9]. «0собенно значимы для творчества: 1) синтетическая способность - новое видение проблемы, преодоление границ обыденного сознания; 2) аналитическая способность - выявление идей, достойных дальнейшей разработки; 3) практические способности умение других убеждать в ценности идеи (“продажа"). Важно, чтобы у человека они находились в гармоничном сочетании, иначе превалирование аналитической способности делает человека блестящим критиком, но не творцом, а превалирование синтетической способности приводит к выдвижению массы новых идей, не обосно- 
ванных исследованиями и бесполезных. Практическая способность без двух предыдущих может привести к проталкиванию ярко представленных, но недоброкачественных идей» [10, с. 224].

Креативные действия совершаются людьми в реальных и многообразных общественных условиях, оказываясь вплетенными в нескончаемую череду человеческих взаимодействий, распределенных во времени и пространстве. Исследуя перспективы роста значения творчества, следует помнить, что центры ярко выраженной креативности, отличающиеся стремлением к поддержке и стимулированию всякого разнообразия и новизны, толерантностью к личностным проявлениям, отлаженной информационной коммуникацией - обычно сосредоточенные в крупных городах развитых стран - соседствуют с крайне консервативными государствами, регионами, сообществами. Общество знаний и творческого труда остается пока лишь ориентиром будущего. Подавляющее большинство жителей земли далеки не только от сознательной и регулярной творческой деятельности, но даже от элементарного осознания своих креативных способностей. Совершаемые креативные действия в консервативной среде не воспринимаются как полезные зачатки созидательного и ценного творчества и либо никак не оцениваются, либо подвергаются осуждению, высмеиванию и всяческой критике.

В тех развитых общественных центрах, где креативность приветствуется, понимается, развивается и находит каждодневное и разнообразное применение, где значительные силы прикладываются для поиска по всему миру наиболее творчески одаренных, талантливых людей, существует много острых проблем. Например, нередко формируются условия жесткой конкуренции, когда людям, чтобы сохранить свой статус, удержаться в креативном сообществе, определенной среде, приходится много работать, подчиняя труду все свободное время. Те, кто не желает или не способен подстраиваться под динамично меняющийся экономический, социальный, политический заказ, рыночную конъюнктуру, остаются невостребованными и нередко обречены на нищенское существование на пороге царства изобилия. Как подчеркивает Р. Флорида, обратной стороной прогресса может быть не личная свобода, а технологии и свободный рынок, принуждающие людей работать быстрее и напряженнее, оставляющие все меньше времени на общение и личные интересы, разрушающие индивидуальные связи и наносящие ущерб городам и сообществам, в которых мы живем [7, с. 31].

Современная трудность массового развития креативности связана с общим эффектом рассеивания и атомизации креативности на фоне некоторого измельчания креативных личностей, снижения числа значимых общественных фигур, общепризнанных авторитетов. Как говорилось выше, разнообразие индивидуальных жизненных планов, культурный плюрализм, прогрессирующая функциональная и стратификационная дифференциация и иные разобщающие факторы препятствуют формированию сильных общественных движений, наделенных твор- ческим потенциалом, открытых к принятию в свои ряды людей, стремящихся к развитию собственной креативности, ищущих полезные формы выражения и применения своих способностей. Существует потребность в создании групп, готовых оказать безвозмездную поддержку людям в реализации креативных способностей на общее благо.

Слабым местом немалого числа творчески ориентированных интеллектуалов всегда была неспособность к долговременной самоорганизации, солидарности, совместному отстаиванию групповых интересов, нежелание брать на себя ответственность за судьбу общества и стремление скрыться за многословием и громкими лозунгами. Склонность к интригам и распрям, краткосрочным союзам этому способствует.

Рассеянная, атомизированная, эгоистическая креативность ведет к растрате ресурсов, умножению рисков и социальному распаду, социальной безответственности не только бизнеса, но и государственных институтов.

В столь противоречивой ситуации трансформацию ценностей, пусть и растущей части общества, рано воспринимать как долгосрочное и многообещающее явление. Расцвет креативности может окончиться простым обособлением группы очередных «меньшинств», с учетом того, что в самой идее выделения «креативного класса» и иных особых групп заложена претензия на уникальность, потенциальное стремление отгородиться от общественного большинства, замкнутость и враждебность к «чужакам». Это особенно заметно, когда дело доходит до профессиональной деятельности, конкуренции на рынке труда, распределения материальных благ. Как говорит Х. Йоас, подразумевая массовое развитие креативности, «решающее значение имеет вопрос о том, не оказывается ли общественная действительность в стороне от этой трансформации ценностей или же они пронизывают и изменяют эту действительность, возможно даже получая от нее поддержку» [5, с. 281].

Необходимы постепенно накапливающиеся последовательные изменения человеческого поведения и общественной организации, способствующие развитию креативности, а также ясное понимание общественных изменений, связанных с ними возможностей и рисков.

Система мер, поддерживающих тенденции развития массовой креативности, должна вырабатываться и реализовываться в первую очередь институтами воспитания, образования и культуры. Современному и будущему образованию необходимо искать методы раннего выявления и персонифицированного развития творческих начал, талантов, способностей. Но надо избегать как элитарности такого образования, так и возможного излишнего ранжирования и отбора тех или иных способностей, талантов по экономическим, политическим, идеологическим и прочим утилитарным признакам. То, что кажется хорошим и выгодным в настоящем, далеко не всегда ведет к благополучному будущему; наоборот, сегодня невостребованные способности и качества могут послужить фундаментом для строительства более гармоничного, справедливого общества в будущем. 
Чтобы всерьез говорить о переходе к креативной экономике, обществу знаний, постиндустриальному обществу и т. д., необходимо согласовать понимание креативности в разных ее проявлениях. Разработать взаимосвязанные критерии позитивной, продуктивной креативности, применительно к разным сферам ее реализации. Несомненно, креативность, присущая каждому человеку, способна развиваться и проявляться в разной степени в зависимости от конкретной личности, сферы реализации (искусство, наука, техника, управление, предпринимательство и т. п.) и окружающих условий. Поэтому важно ранжировать интенсивность проявления креативности и связать с продуктивностью и пользой.

Вместе с тем надо помнить, что креативность важна не только для чего-то конкретного, но и сама по себе, то есть для полноценного раскрытия позитивного потенциала личности, гармоничного развития человека и общества. При этом важно учитывать самодостаточную креативность (рассматривать личностное самовыражение в быту и на досуге), самовыражение, не имеющее какой-то конкретной, непосредственной экономической ценности (в виде продукта, услуги, прибавочной стоимости и т. п.), однако полезное для психического здоровья личности и общества в целом.

Перспективы массового развития творческих способностей должны основываться на поиске баланса между свободой личного самовыражения и соблюдением интересов окружающих. В этом отношении X. Йоас справедливо подчеркивает, что «демократическая культура требует толерантности по отношению к самым различным стилям жизни и большого пространства возможностей для автономного выбора этих стилей жизни. И, конечно, нельзя отождествлять неизбежно множественные стили жизни с поддающимися универсализации требованиями ко всему коллективу - и, тем не менее, в них должны оставаться какие-то требования к другим людям. Там, где этот остаток исчезает, культурная инновация вырождается в образование частных анклавов и тем самым освобождает общественное пространство для тех, кто хочет утвердить в нем свои принципы» [5, с. 285]. Как подавленная окружающей средой креативность может воплощаться в агрессии и стремлении к разрушению, так и отсутствие всяких сдерживающих факторов и обязательств перед окружающими людьми приводит к хаосу, в котором неизбежно выделяются личности и группы, навязывающие обществу свои точки зрения, идеи и волю.

Стремясь к развитию креативности, важно помнить, что не сами по себе материальные ценности, деньги важны для творчества, а инвестиции в благоприятные, комфортные условия, инфраструктуру, способствующую высвобождению креативности и реализации идей. Погоня же за личным материальным достатком как главная цель - скорее показатель творческой деградации и попросту низкокачественной имитации (а не творчества), целенаправленного создания коммерчески выгодных, но низкокачественных продуктов и услуг.

В конечном счете сохранение тенденций и успешность развития массовой креативности зависит от того, удастся ли поддерживать высокие темпы экономического роста, обеспечивающего приемлемый уровень общественного благосостояния. Важную роль играет технический прогресс. Известно, что во многом именно новые технологии высвобождают время и силы для творчества, дают возможность перейти от изнуряющего, однообразного труда к творческой активности, переложить на технические средства всю тяжелую работу. Поэтому главный вызов зарождающемуся и пропагандируемому расцвету креативности заключается в самой способности растущего числа творчески ориентированных людей самоорганизоваться и направить свои таланты на решение общественных проблем. Невозможно бесконечно заниматься разнообразным самовыражением, надеясь, что условия для такой беззаботной жизни создаст ктото другой. От способности креативных личностей создать благоприятные условия за счет полезных научных открытий, всевозможных созидательных инноваций, обеспечиваемых преемственностью знаний, опыта, основанных на важных традициях и ценностях, гибких социальных связях, зависит будущее развитие массовой креативности. Несомненно, что в тяжелых условиях всегда побеждает авторитарная дисциплина, а не творческая свобода. Значит единственный путь фактического распространения креативного мышления и разнообразной активности - дальнейшее улучшение условий жизни всех слоев населения.

\section{Список литературы}

1. Дружинин В.Н. Психология общих способностей. - СПб.: Питер, 2007.

2. Пономарев Я.А. Психология творчества // Тенденции развития психологической науки. - М.: Наука, 1988.

3. Китаев-Смык Л.А. Факторы напряженности творческого процесса // Вопросы психологии. - 2007. - № 3.

4. Вильчек В.М. Алгоритмы истории. - М.: Прометей, 1989.

5. Йоас Х. Креативность действия. - СПб.: Алетейя, 2005.

6. Маслоу А. Психология бытия. - М.: Рефл-бук, 1997.

7. Флорида Р. Креативный класс: люди, которые меняют будущее. - М.: Классика-XXI, 2007.

8. Зеленцова Е. На пути к творческой экономике [Электронный ресурс]. - Режим доступа: http://www.creativeindustries. $\mathrm{ru} /$ rus/publications/creative_industries_way

9. Sternberg R.J., Lubart T.I. Investing in creativity // American Psychologist. - 1996. - Vol. 51.

10. Ильин Е.П. Психология творчества, креативности, одаренности. - СПб.: Питер, 2009. 